\title{
Single-current-sensor-based active front-end-converter-fed four quadrants induction motor drive
}

\author{
JOSEPH KIRAN BANDA* and AMIT KUMAR JAIN \\ Department of Electrical Engineering, Indian Institute of Technology Delhi, New Delhi 110016, India \\ e-mail: josephkiran.b@gmail.com; amitjain@ee.iitd.ac.in
}

MS received 16 March 2016; accepted 28 September 2016

\begin{abstract}
Induction motor (IM) is a workhorse of the industry, whose dynamics can be modified close to that of a separately excited DC machine by field-oriented control technique, which is commonly known as vector control of induction machine. This paper presents a complete performance of the field-oriented control of IM drive in all four quadrants with a single-current-sensor-based active front end converter whose work is to regulate DC link voltage, draw pure sinusoidal currents at unity power factor and to facilitate bi-directional power flow between the grid and the drive. The entire system is completely modelled in MATLAB/SIMULINK and the results are discussed in detail. The vector control analogy of the back to back converters is highlighted along with the experimental results of field-oriented control of induction machine using a dsPIC30F6010A digital signal controller.
\end{abstract}

Keywords. Field-oriented control; vector control of induction motor; active front end converter; power factor correction; four-quadrant drive; grid-voltage-oriented control.

\section{Introduction}

In recent years, there has been a tremendous rise in the development of fast switching semiconductor switches and fast acting digital signal processors, which has created a revolution in the area of electrical drives. Even though AC drives are sometimes more expensive, they are lot more reliable than DC drives and are being used in many industrial applications like high-performance variablespeed applications, fans, blowers, rolling mills, textile mills, etc. An induction machine, especially with a squirrelcage rotor, is best suited for these applications as it is simple, rugged, reliable, efficient, compact and economical [1]. However, the performance of DC drives in terms of decoupled control of flux and torque can also be achieved by employing a field-oriented control (FOC) technique on the induction machine, which is very popular and is in practice for many years.

Sinusoidal currents flowing in the motor windings are followed by moving along with a rotating reference frame whose angular frequency is the same as the frequency of the currents, which results in AC quantities transforming into DC quantities by decoupling into torque and flux components [2]. The FOC technique makes the machine to deliver higher performance as the torque speed characteristics of the machine are modified in such a way that maximum available amount of torque can be used to reach any

*For correspondence operating speed. Hence one can imagine modified speed torque characteristics of an induction motor (IM) as a box whose edges are peaks of torque and speed in positive and negative directions. However, it is self-explanatory that the entire box of speed and torque characteristics is traced only when the drive is said to operate in all four quadrants (forward motoring, reverse generation, reverse motoring and forward generation). Regeneration is also observed during speed reversals, where active power can be extracted from the drive and sent back to the grid by employing an active front end converter (FEC), which results in power savings with the drive.

Active FEC is a PWM converter, which is looked upon as a voltage source of variable magnitude and phase connected to grid voltage using coupling inductors. The salient features observed by using this converter are DC link voltage regulation, sinusoidal currents from the grid, bidirectional power flow and unity power factor (UPF) at grid terminals [3]. This serves at the front end side of the drive; hence the name active FEC and the control involved is termed as grid-voltage-oriented control.

This paper presents a complete picture of the modelling of the plant (induction machine and grid), controller design and simulation study of a single-current-sensor-based active FEC-fed four quadrants IM drive. All the transient and steady-state simulation results in all the control variables at motor side as well as grid side are shown when the drive operates in four quadrants. This paper also throws some light on comparing the similarities involved in FOC and grid- 
voltage-oriented control, which simplified the design of controller gain variables of outer and inner control loops, along with experimental results of FOC of induction machine using a dsPIC30F6010A digital signal controller. Reducing a current sensor on the FEC helps in reducing cost of the drive; suitable logic added makes the drive a fault-tolerant one so that even if one current sensor fails, the drive will continue to run, delivering the desired performance [4].

\section{System configuration}

Figure 1 shows the complete system under study, which has three-phase IGBT bridge-based back to back converters with the motor on one side and active grid on the other side coupled with series inductors. It also includes a control block diagram of both converters, highlighting the single-current-sensor topology of FEC along with the similarities involved in the desired control of the whole system. When looked at from DC link, one converter looks like a mirror image of the other converter. The only difference is that the motor is passive, but the grid is active.

\subsection{Modelling of the plant system}

Modelling of the plant is the fundamental step in the design, analysis and control of any system. The level of precision that one could achieve when the developed control is tested on hardware purely depends on the design stage of the plant model.

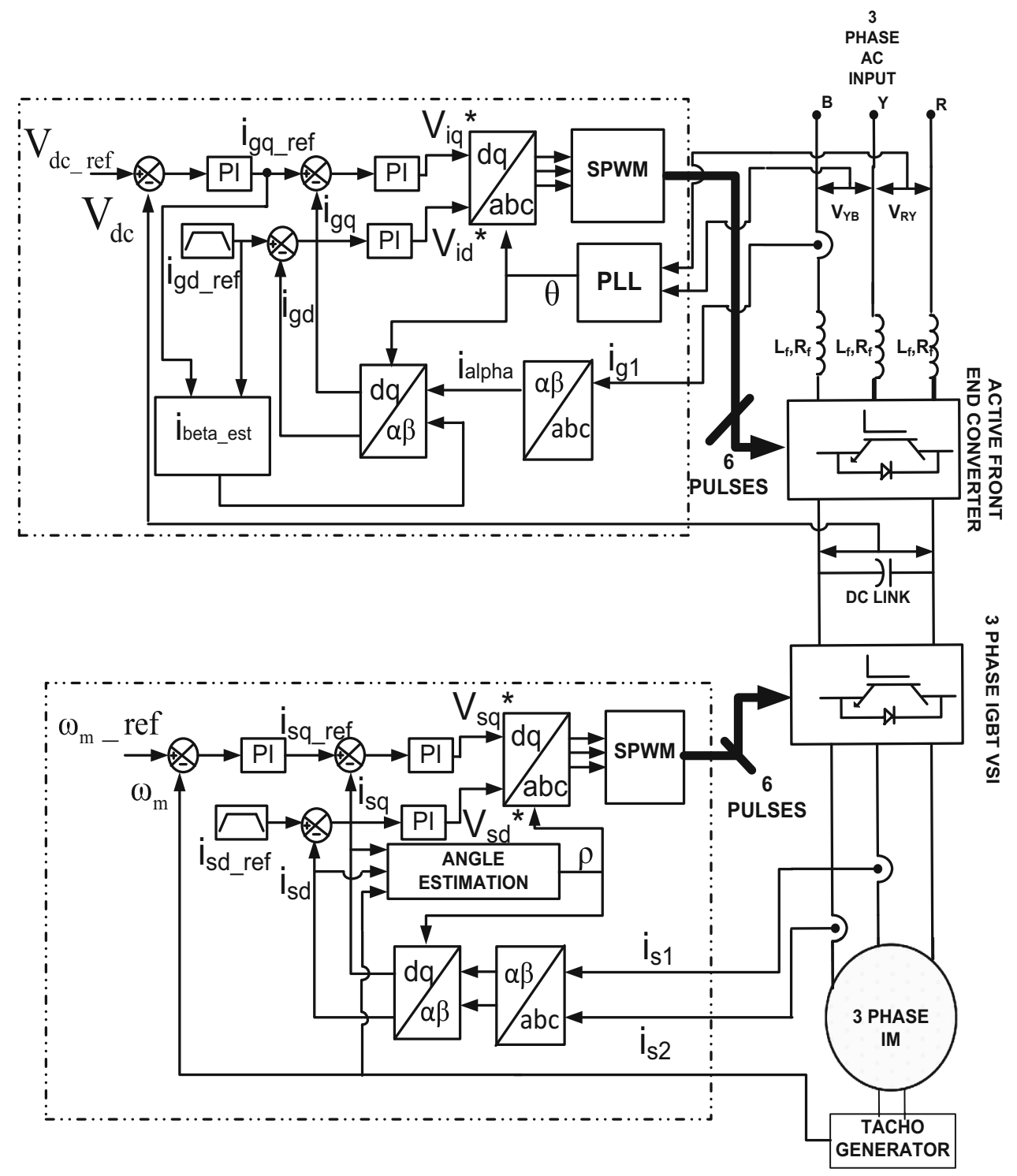

Figure 1. Block diagram of single-current-sensor-based FEC-fed FOC of four quadrants induction motor drive. 
The following discussion provides all the necessary modelling equations starting with FOC of IM and then presenting equations related to FEC. Symbols used in the equations are defined immediately after the modelling equations.

$$
\begin{gathered}
M_{d}=\left(\frac{2}{3}\right)\left(\frac{P}{2}\right)\left(\frac{L o}{1+\sigma_{r}}\right) i_{s q} i_{m r} \\
i_{m r}-i_{s d}+T_{r} \frac{d}{d t} i_{m r}=0 \\
\omega_{s}-\omega_{e}=\left(\frac{i_{s q}}{T_{r} i_{m r}}\right) \\
V_{s d}=R_{s} i_{s d}+\sigma L_{s} \frac{d}{d t} i_{s d}-\omega_{s} \sigma L_{s} i_{s q}+(1-\sigma) L_{s} \frac{d}{d t} i_{m r} \\
\psi_{s q}=L_{s} i_{s q}+\sigma L_{s} \frac{d}{d t} i_{s q}+\omega_{s} \sigma L_{s} i_{s d}+(1-\sigma) L_{s} i_{m r} \omega_{s}
\end{gathered}
$$

where $R_{S}$ is stator resistance, $L_{s}$ is stator inductance and $L_{o}$ is magnetizing inductance; $\sigma$ and $\sigma_{r}$ are resultant leakage constant and rotor leakage constants, respectively, $M_{d}$ is developed electromagnetic torque, $P$ is the number of poles, $\psi_{r}$ is the rotor flux space phasor, $T_{r}$ is the rotor time constant, $V_{s d}, i_{s d}, V_{s q}, i_{s q}$ are components of stator voltage and stator current along the $d$-axis, $q$-axis and $i_{m r}$ is the current responsible for rotor flux; $\omega_{s}$ and $\omega_{e}$ are the speeds of rotor flux and the rotor itself in electrical radians per second. Equations (1)-(6) present modelling of IM in a rotating reference frame, which is the rotor flux in this paper.

$$
\begin{gathered}
V_{i d}=V_{g d}-R_{f} i_{g d}-L_{f} \frac{d}{d t} i_{g d}+\omega_{g s} L_{f} i_{g q} \\
V_{i q}=V_{g q}-R_{f} i_{g q}-L_{f} \frac{d}{d t} i_{g q}-\omega_{g s} L_{f} i_{g d} \\
P_{g r i d}=\frac{2}{3}\left(V_{g d} i_{g d}+V_{g d} i_{g d}\right) \\
C \frac{d}{d t} V_{d c}=\frac{2}{3}\left(\frac{V_{g d} i_{g d}+V_{g q} i_{g q}}{V_{d c}}\right)-\frac{P_{l o a d}}{V_{d c}} .
\end{gathered}
$$

Equations (7)-(10) show the governing equations of active FEC connected to the grid using coupling inductors $L_{f}$ and grid resistance $R_{f} . V_{g d}, V_{i d}, V_{g q}, V_{i q}$ are the grid and converter voltages resolved along the $d$-axis and $q$-axis of the voltage-oriented reference frame; $\omega_{g s}$ is grid angular frequency, $C$ being the DC link capacitance, and $V_{d c}$ is the DC link voltage; $i_{g d}, i_{g q}$ are the reactive and active components of grid line current resolved along $d$ - and $q$-axis. $P_{\text {grid }}$ and $P_{\text {load }}$ are the active powers drawn or supplied to the grid and load which is IM in this case.

\subsection{FOC-based IM drive}

Generally, one can imagine operation of three-phase IMs as sinusoidal three-phase input currents applied to the stator. This time-variant signal creates a rotating magnetic field, and the speed of the rotor is going to be a function of the rotating flux vector. From the stationary perspective the stator currents and the rotating flux vector look like AC quantities. Instead, one must picture himself running inside a motor with the same speed as the rotating flux vector that is generated by three-phase stator quantities. Then all the three-phase time-varying quantities look stationary. The feedback variables are two stator currents and mechanical speed. They can be obtained from two hall sensors and a tacho generator (coupled on the same shaft). Using the information of the two stator currents and motor speed, slip speed is estimated and thereby synchronous speed and angle of transformation can be evaluated. With the new angle of transformation obtained, a reference voltage at desired phase is generated using a voltage source converter, which makes the motor to reach desired speed, showing good dynamic performance, which suits applications like fans, blowers, rolling mills, textile mills, etc. [5]. Figure 2a shows a phasor diagram of FOC where $d$-axis is oriented along the rotor flux.

\subsection{Single-current-sensor-based FEC}

An active FEC or grid-connected converter serves mainly to improve power quality of the drive at utility mains by drawing pure sinusoidal currents at UPF. DC link voltage is the medium through which active FEC control works. Whenever there is a power flow into the motor, DC link voltage falls down; thereby FEC draws the only active power component (at UPF) to regulate DC link to reference values. If there is a sudden dip in the active power requirement of the motor, DC link voltage rises and thereby FEC pushes extra active power into the grid, making $V_{d c}$ regulated. Figure $2 b$ shows the phasor diagram of FEC where $q$-axis is oriented along voltage phasor. To make a cost-effective, fault-tolerant and robust drive, one must eliminate or reduce the number of sensors used to implement the control. Literature survey was carried out in eliminating one current sensor out of the two. Recent publications suggested that only one current sensor on grid terminals would be enough to implement FEC by estimating required variables from the available control variables [6].

$$
i_{\text {beta_est_grid }}=i_{g d \_r e f} \sin \theta+i_{g q \_r e f} \cos \theta
$$

where $\theta$ is the angle of the transformation used in the FEC. As $i_{\text {beta_est_grid }}$ is obtained from Eq. (11), one current sensor can be eliminated. The convergence is suitably justified as present samples of $i_{g d \_r e f}$ and $i_{g q \_}$ref would be similar to next samples of $i_{g d}$ and $i_{g q}$, respectively. 
Suitable simulation results proving the convergence of this logic are shown in the following sections.

\subsection{Control analogue of back to back converters}

By closely observing the block diagram presented in figure 1, it can be stated that the line current of the grid is totally decoupled as $q$-axis component and as $d$-axis component with the FEC. Hence, two PI current controllers with necessary feed-forward terms are employed to control active and reactive components of current, respectively. The entire scenario looks similar and analogous to FOC of induction machine, where $q$-axis current controls torque or active component and $d$-axis controls flux or reactive component of the machine. To regulate DC link voltage using FEC, one more outer loop has to be employed, which is just similar to speed of outer loop in case of FOC of IM. Figure 3 highlights the control analogy of FEC and FOC, in

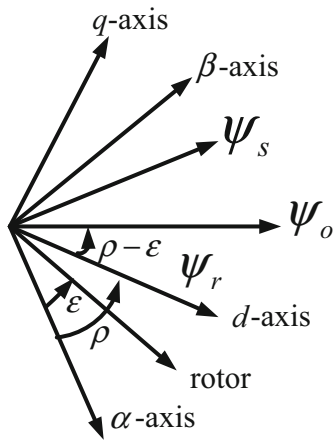

(a)

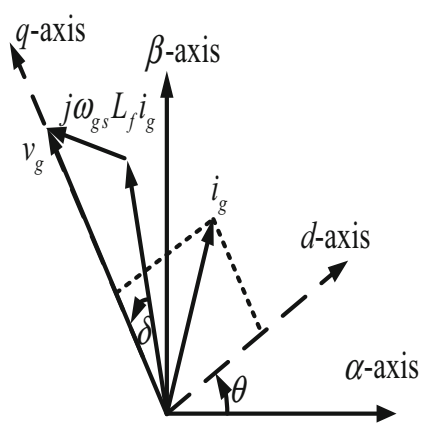

(b)
Figure 2. Phasor diagrams showing rotor-flux-oriented FOC and grid-voltage-oriented FEC. (a) Phasor diagram of FOC. (b) Phasor diagram of FEC. which DC link is at the centre and controls of the FEC and FOC are mirror images of each other.

\subsection{FEC-fed four-quadrant IM drive}

With an active FEC employed, IM drive is now capable of operating in all four quadrants (forward motoring, reverse generation, reverse motoring and forward generation). During motoring modes, active power flows from the grid to motor and during generation modes it is vice versa. However, in all the modes, currents drawn from the grid are sinusoidal in nature at UPF. Figure 4 shows a theoretical understanding of four quadrants of the drive with torque on $Y$-axis and mechanical speed on $X$-axis.

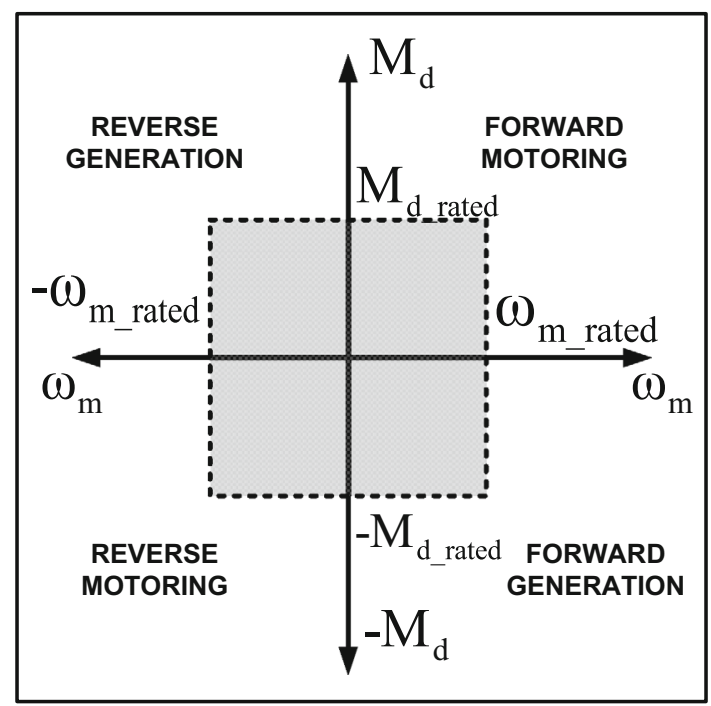

Figure 4. Four-quadrant operation of IM drive.

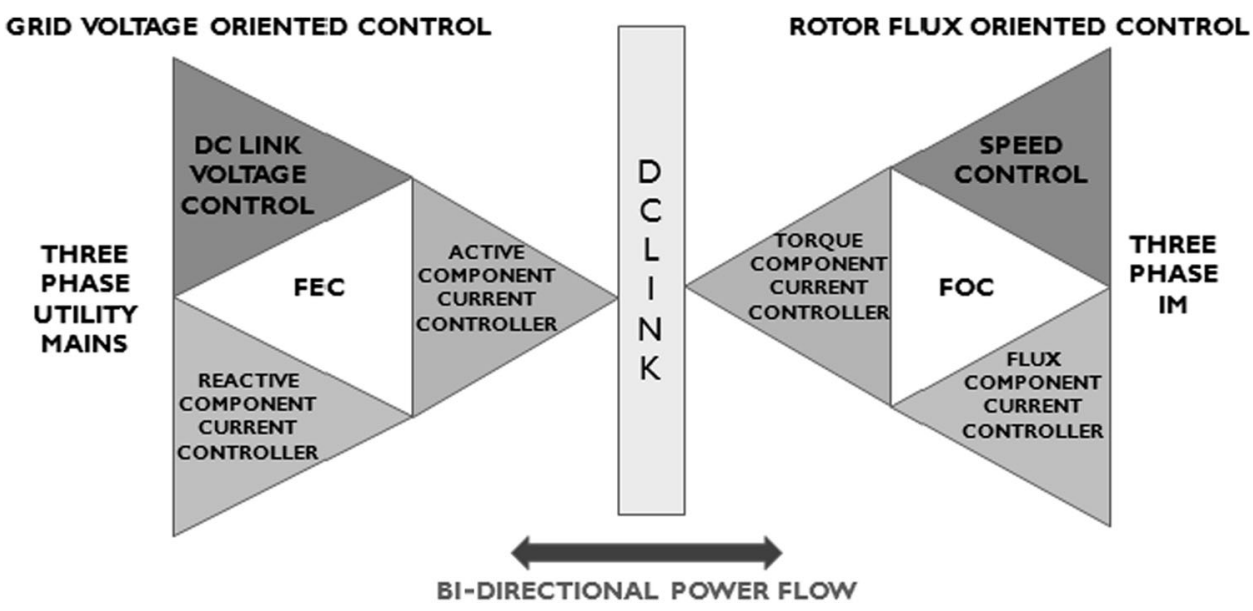

Figure 3. Control analogy of FEC and FOC. 


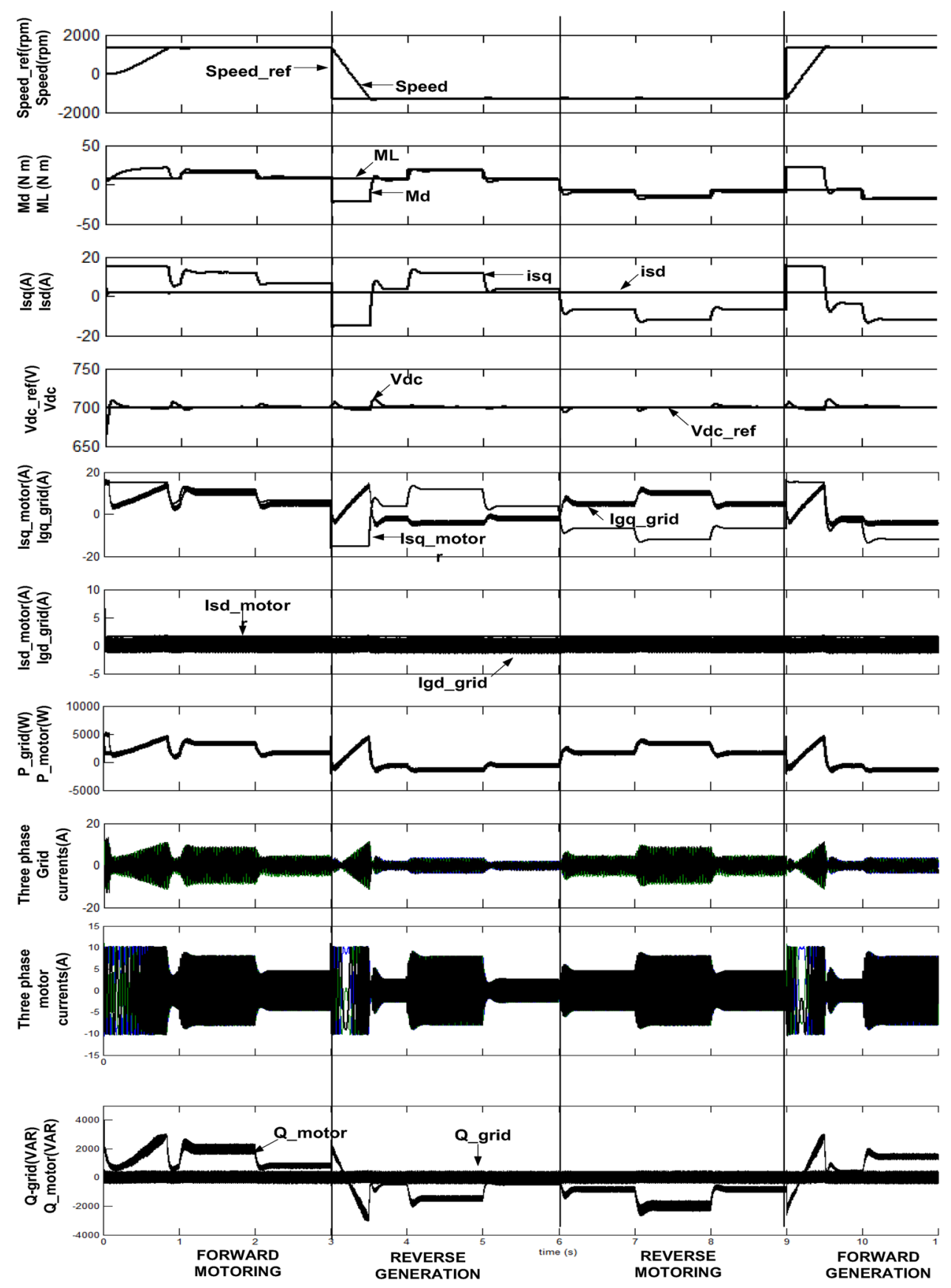

Figure 5. Simulation results of single-current-sensor-based active front-end-converter-fed four quadrants induction motor drive.

\section{Simulation results and discussion}

Induction machine parameters used for simulation study are $P_{\text {motor }}=3.7 \mathrm{~kW}$, rated speed $=1430 \mathrm{rpm}, V_{(L-L) r m s}=$ $415 \pm 10 \% \quad \mathrm{~V}, \quad I_{(\text {Line }) r m s}=7.5 \quad \mathrm{~A}, \quad R_{\text {s/phase }}=6.673 \Omega$, $R_{r / \text { phase }}=3.491 \Omega, L_{o / \text { phase }}=0.673 \mathrm{H}, L_{l s / \text { phase }}=0.0272$ $\mathrm{H}, L_{l r / \text { phase }}=0.0272 \mathrm{H}, J=0.0532 \mathrm{~N} \mathrm{~m} \mathrm{~s} /$ mech.rad and $B=0.0156 \mathrm{~N} \mathrm{~m} \mathrm{~s} / \mathrm{mech} . \mathrm{rad}$.
It is generally preferred to have a FEC whose power rating is a little higher than that of the IM drive attached to it. Parameters of active FEC used for simulation study are $P_{\text {grid }(\text { rated })}=5 \mathrm{~kW}$, grid voltage $/$ phase $(\mathrm{rms})=230 \mathrm{~V}$, $\omega_{g s}=314 \mathrm{rad} / \mathrm{s}, C=6750 \mu \mathrm{F}, L_{f}=6 \mathrm{mH}, R_{f}=0.6 \Omega, F_{s}$ (switching frequency) $=10 \mathrm{kHz}$ and $\mathrm{DC}$ link voltage $\left(V_{d c}\right)=700 \mathrm{~V}$.

Figure 5 presents steady-state and transient simulation results of all control variables involved in active FEC-fed 


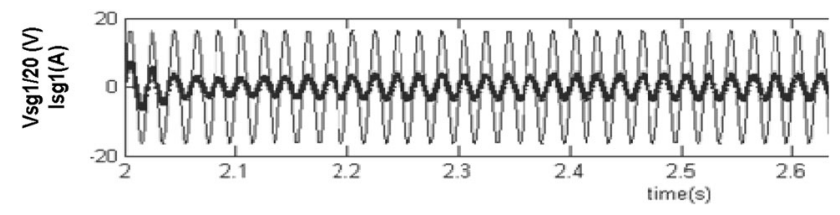

Figure 6. Simulation results of grid voltage and current of FEC fed FOC of IM drive.

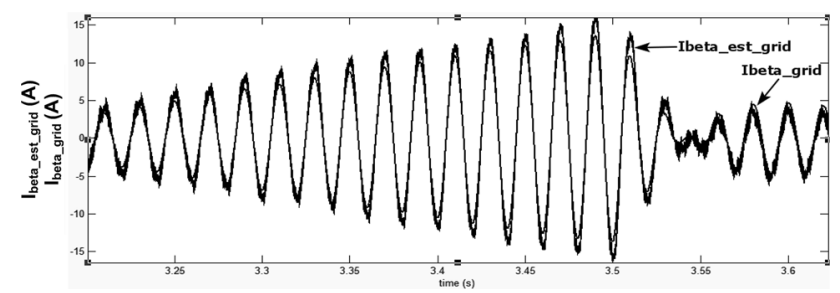

Figure 7. Simulation results of $I_{\text {beta_est_grid }}$ and $I_{\text {beta_grid current }}$.

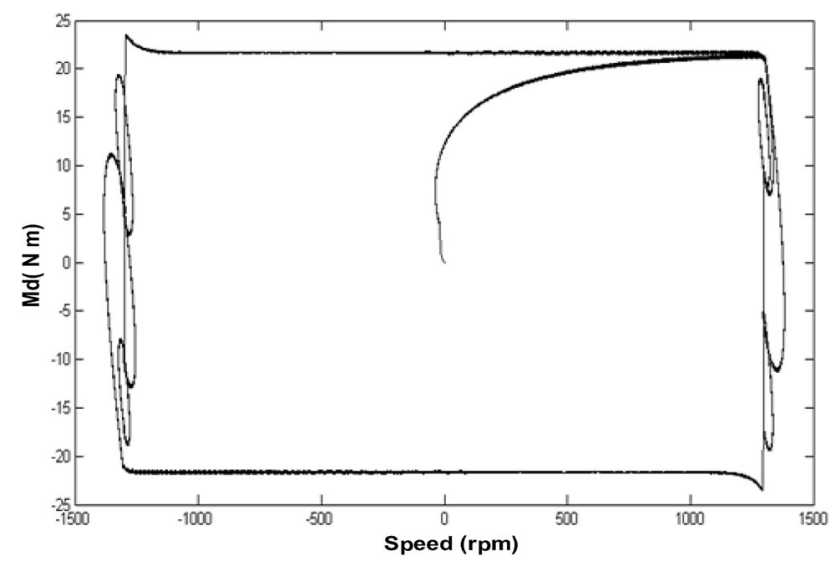

Figure 8. Simulation results show four-quadrant operation of IM drive.

four-quadrant IM drive. From time 1 to $3 \mathrm{~s}$, IM operates in a forward motoring mode, 3 to $6 \mathrm{~s}$ in reverse generation mode, 6 to $9 \mathrm{~s}$ in reverse motoring mode and 9 to $11 \mathrm{~s}$ in forward generation mode. In forward motoring mode, as the drive is operated with FOC, rated $i_{s q}$ (means rated torque) is used by the machine to reach the reference speed in less than a second. As $i_{s q}$ and $i_{s d}$ are totally decoupled, there would be no change in $i_{s d}$ even when there is a change in speed reference or load torque. To obtain UPF at grid side with FEC, $i_{g d \_r e f}$ is made zero and the result thus obtained is presented in figure 6 .

Figure 7 shows simulation results of $i_{\text {beta_est_grid }}$ similar to $i_{\text {beta_grid current, }}$ justifying the convergence of Eq. (11). Referring back to figure 5, it is clear that active power required by the drive $\left(P_{\text {motor }}\right)$ and active power drawn or supplied from the grid $\left(P_{\text {grid }}\right)$ are the same. However, because of control, reactive power requirement of the drive $\left(Q_{\text {motor }}\right)$ and reactive power drawn from the grid ( $Q_{\text {grid, }}$, which is zero at UPF operation) are independent. As full torque (constant) is used by IM to reach reference speed, $P_{\text {motor }}$ follows the profile of speed; as the voltage of the grid is constant, currents drawn from the grid also follow the profile of speed to make power required by the drive and power drawn from grid equal. To change the quadrant of operation, speed reversal is implemented, which undergoes quick reversal with regenerative braking, pushing power back to the grid, which can be seen from time 3 to $3.6 \mathrm{~s}$. As rated negative torque is used to attain speed reversal, there is a small period of time when speed is positive and torque is negative, which is termed as a regenerative period, which is responsible for providing savings in FEC-fed FOC of IM drives. Similarly, by changing either speed or load torque direction, all four quadrants of operation are presented clearly. The torque speed characteristics traced by the drive from time 0 to $11 \mathrm{~s}$ are shown in figure 8 , which justifies the four-quadrant operation of the drive.

\section{Experimental results and discussion}

FOC of a three-phase IM has been implemented using a dsPIC30F6010A digital signal controller at $2 \mathrm{kHz}$ switching frequency. Following experimental results present transient and steady-state response of the drive with indirect FOC implemented.

Experimental results in figure 9a show transient response of $\mathrm{R}$ phase line current, $i_{s d}$, reference speed and actual speed for step change in reference speed. It is clear that $i_{s d}$ loop is initiated a little before the speed loop is initiated, which means the torque command is given only after rated flux is established inside the machine. Figure $9 \mathrm{~b}$ shows the electrical angle as well as the sine and cosine of the same used for transformation of variables required to implement FOC. Figure $9 \mathrm{c}$ and $\mathrm{d}$ shows transient response of $\mathrm{R}$ phase line current, $i_{s q}, i_{s q \_r e f}, i_{s d}$, reference speed and actual speed for step change in reference speed. These results justify decoupled operation of torque and flux, similar to a separately excited DC machine. Figure 9e shows transient response of $\mathrm{R}$ phase line current, $i_{s q}, i_{s q \_r e f}$, reference speed and actual speed for two different step changes in reference speed. Figure 9f shows current controller responses of $i_{s d}$ and $i_{s d_{-} \text {ref }}$. The noise on $i_{s d}$ when there is a step increment in the motor speed is due to the error in estimation of position obtained from the tacho generator. The ideal decoupled nature can be seen by using position encoders or by implementing a sensorless scheme.

Figure 10a shows steady-state response of speed, converter line to line voltage and $\mathrm{R}$ phase line current. Figure $10 \mathrm{~b}$ shows transient response of $\mathrm{R}$ phase line current, $i_{s q}$, reference speed and actual speed for step decrement in reference speed.

Figure 11a and $\mathrm{b}$ shows transient response of speed, reference speed and R phase line current $i_{s d}$ and $i_{s q}$ for step change 


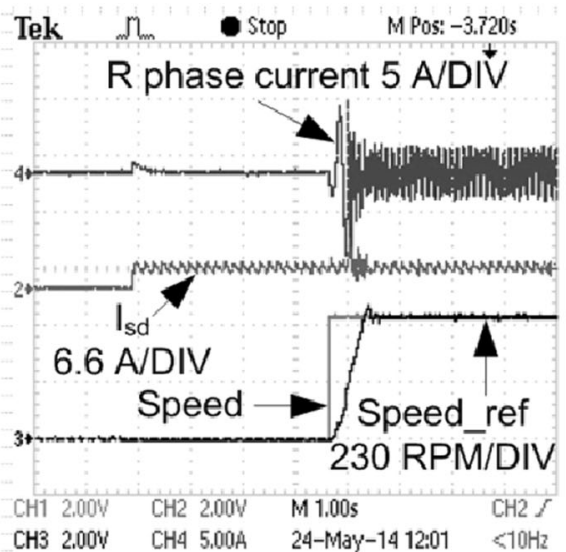

(a)

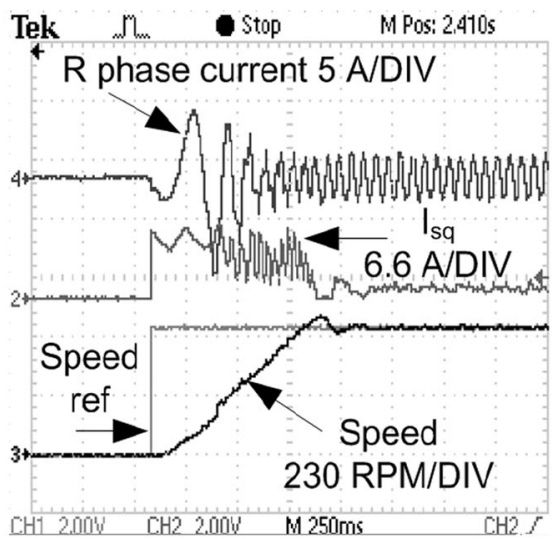

(c)

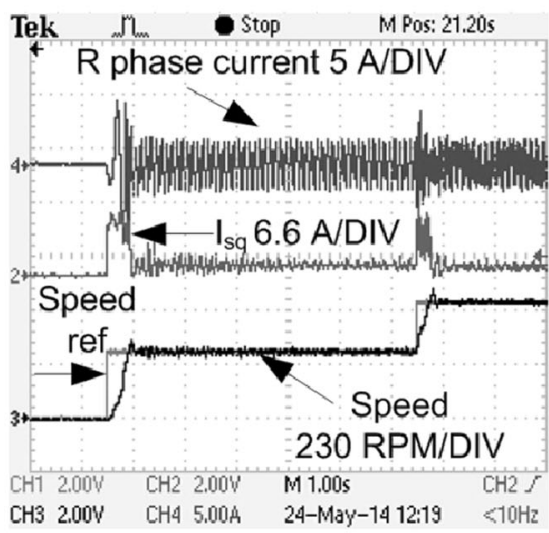

(e)

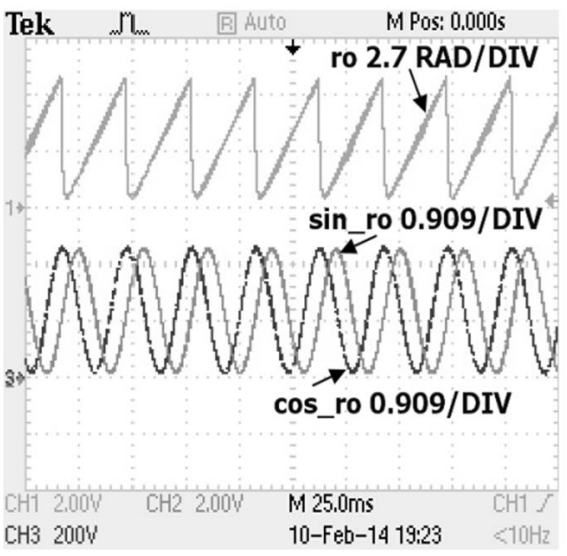

(b)

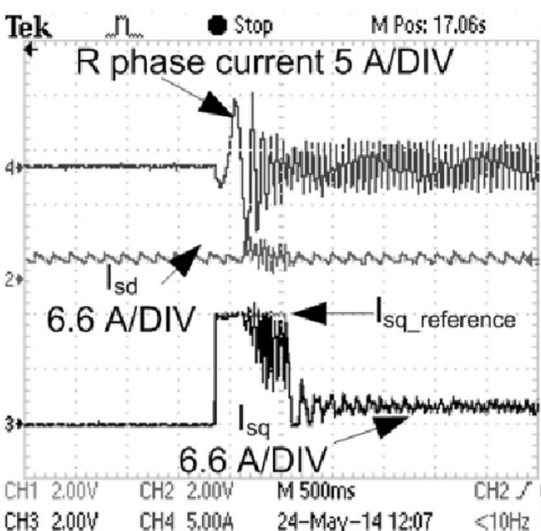

(d)

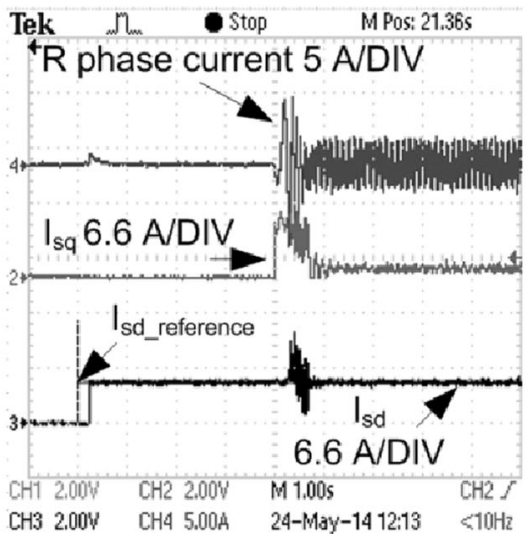

(f)

Figure 9. Experimental results showing transient and steady-state responses of control variables with a step increase in speed.

in load. It is clearly understood that $i_{s d}$ variable, which takes care of flux inside the machine, is unchanged when there is load change; $i_{s q}$ variable, which traces $i_{s q}$ ref obtained from the outer speed loop, maintains speed at the desired reference value by increasing proportionally to the increment in the load.
Figure 11c and $\mathrm{d}$ shows transient response of $\mathrm{R}$ phase line current $i_{s d}, i_{s d \_r e f}, i_{s q}, i_{s q \_r e f}$ for different step changes in load. Experimental results that show all the controller variables are plotted in an oscilloscope using DAC ports available in dsPIC30F6010A. 


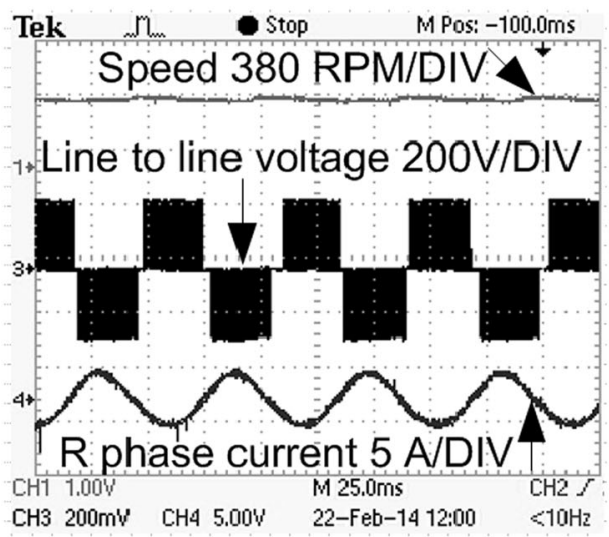

(a)

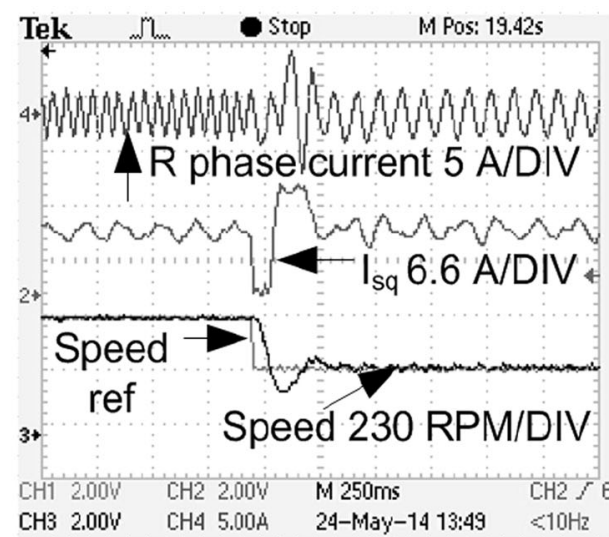

(b)

Figure 10. Experimental results showing transient and steady-state responses of control variables with step decrease in speed.

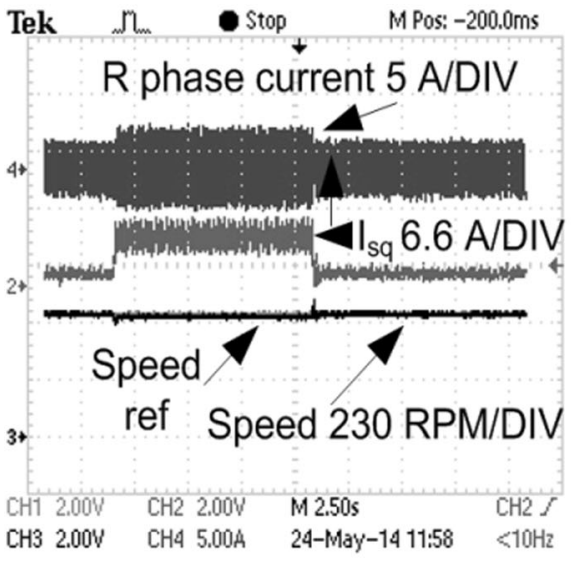

(a)

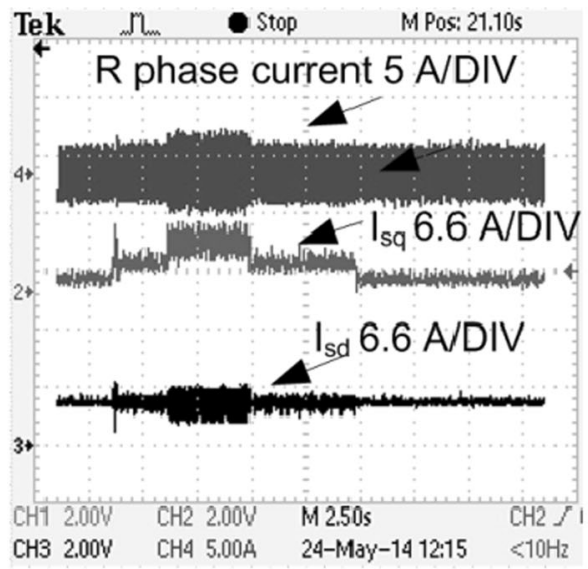

(c)

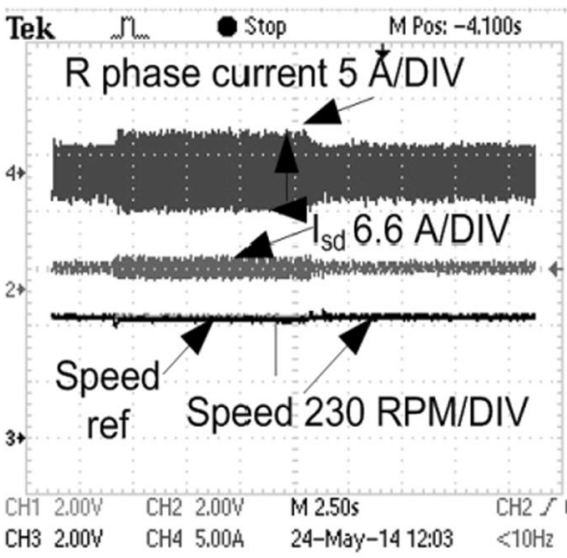

(b)

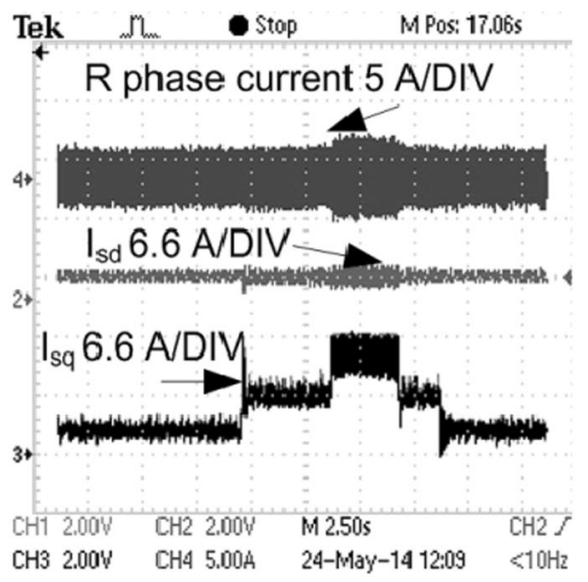

(d)

Figure 11. Experimental results showing transient and steady state responses of control variables with step change in load.

\section{Conclusions}

Single-current-sensor-based active FEC-fed FOC of a four quadrants induction machine is completely modelled using MATLAB/SIMULINK and the simulation results are discussed in detail. The vector control analogy of the back to back converters is highlighted along with the experimental results of FOC of induction machine using a dsPIC30F6010A digital signal controller. 


\section{List of symbols}

$R_{S}$

$L_{s}$

$L_{o}$

$\sigma$

$\sigma_{r}$

$M_{d}$

$P$

$\psi_{r}$

$T_{r}$

$V_{s d}$

$i_{s d}$

$V_{s q}$

$i_{s q}$

$i_{m r}$

$\omega_{s}$

$\omega_{e}$

$L_{f}$

$R_{f}$

$V_{g d}$

$V_{i d}$

$V_{g q}$

$V_{i q}$

$\omega_{g s}$

C

$V_{d c}$

$i_{g d}$

$i_{g q}$

$P_{\text {grid }}$

$P_{\text {load }}$

$P_{\text {motor }}$ stator resistance per phase

stator inductance per phase

magnetizing inductance per phase

resultant leakage constant

rotor leakage constant

developed electromagnetic torque

number of poles

rotor flux space phasor

rotor time constant

stator voltage along $d$-axis

stator current along $d$-axis

stator voltage along $q$-axis

stator current along $q$-axis

current responsible for rotor flux

speed of rotor flux in electrical radians per

second

speed of rotor in electrical radians per

second

coupling inductance per phase

grid resistance per phase

grid voltage along $d$-axis

converter voltage along $d$-axis

grid voltage along $q$-axis

converter voltage along $q$-axis

grid angular frequency

DC link capacitance

DC link voltage

reactive component of grid line current

along $d$-axis

active component of grid line current along $q$-axis

active power drawn from the grid

active power supplied to load

active power supplied to motor
$Q_{\text {motor }}$

$Q_{\text {grid }}$

$i_{g d \_r e f}$

$i_{g q \_r e f}$

$i_{s d \_r e f}$

$i_{s q \_r e f}$

$F_{s}$

$i_{\text {beta_est_grid }}$

$i_{\text {beta_grid current }}$ reactive power supplied to motor reactive power drawn from the grid reactive component reference of grid line current active component reference of grid line current

flux component reference of motor line current

torque component reference of motor line current

switching frequency of the converters

estimated beta current (grid side)

actual beta current (grid side)

\section{References}

[1] Vas P 1990 Vector control of AC machines. Oxford University Press, Oxford

[2] Leonhard W 2001 Control of electrical drives, 3rd edn, Springer, Berlin

[3] Siva Prasad J S, Bhavar T, Ghosh R and Narayanan G 2008 Vector control of three phase AC/DC frontend converter. Sadhana 33(5): 591-613

[4] Bowling S 2005 An introduction to AC induction motor control using dsPIC30F MCU. AN984, microchip

[5] Bhuvaneswari G, Singh B and Madishetti S 2012 Three phase, two switch PFC rectifier fed three-level VSI based FOC of induction motor drive. In: Proceedings of the IEEE Fifth Power India Conference, pp. 1-6

[6] Mishra H and Jain A K 2014 Single current sensor based vector control of AC/DC front end converter. In: Proceedings of the IEEE PIICON-2014 Conference, New Delhi 